\title{
Severity of whooping cough in England before and after the decline in pertussis immunisation
}

\author{
T M POLLOCK, E MILLER, AND J LOBB \\ Epidemiological Research Laboratory, Central Public Health Laboratory, London
}

SUMmaRY Since the decline of pertussis immunisation, hospital admission and death rates from whooping cough have fallen unexpectedly. Although this might be taken to indicate that the disease is becoming less severe, a comparison of admissions and deaths in England and Wales before and after the decline in immunisation suggests that several factors other than disease severity-a shift in the social class distribution of the disease, an increase in the proportion of milder cases notified, and improved care-were responsible for this. The severity of attacks and the complication rates in children admitted to hospital were virtually unchanged. Very young infants, those from disadvantaged families, and children with chronic illness were at greatest risk.

The 1974-5 outbreak of whooping cough in England affected a population in which $80 \%$ of the children had been immunised against pertussis. At that time fears about whooping cough vaccine caused a dramatic fall in immunisation rates and in consequence a large increase of notifications. Despite this increase the number of deaths has not risen and it has been suggested that the disease may now be less severe. ${ }^{1}$ We investigated the severity of whooping cough before and after the fall in immunisation. Our assessment is based on comparison of hospital admission rates and the clinical features of the disease in children admitted to hospital or dying of whooping cough in England and Wales.

\section{Methods}

Data on hospital admissions were obtained from studies of whooping cough made by the Epidemiological Research Laboratory (ERL) during the outbreaks of 1974-5 and 1977-80. In the 1974-5 outbreak, 94 of the 98 area health authorities (AHAs) in England and Wales took part in an investigation which lasted from October 1974 to March $1975 .{ }^{2}$ During this period the ERL received a copy of each whooping cough notification and sent a questionnaire to the family doctor requesting details of the severity and immunisation state of each case. A second study was made between January 1978 and June 1980 in 21 AHAs. $^{3}$ In this study the homes of children notified as having whooping cough were visited by nurses to record details of the severity of the attack, any admission to hospital, and the family circumstances. Details of immunisation were obtained from AHA records. In both studies details of admissions were obtained directly from the hospital records. The comparison of hospital admissions in the two outbreaks is based on the same 21 AHAs which took part in both surveys.

The analysis of deaths is based on the total deaths from whooping cough in England and Wales notified to the Office of Population Censuses and Surveys (OPCS) during a two year period centred on the peak of each outbreak-viz January 1974 to December 1975, and July 1977 to June 1979. Copies of the death certificates were obtained from the OPCS and further details were requested from the physicians concerned.

\section{Results}

\section{Hospital Admissions}

Rates. In both surveys, $90 \%$ of the notifications in the 21 AHAs were followed up. Hospital records were obtained for $98 \%$ of those admitted in 1974-5 and for $95 \%$ in $1978-80$. Altogether $800(3 \%)$ of the 24435 children followed up during 1978-80 were admitted to hospital and diagnosed as having whooping cough. This rate was only one third of that in 1974-5 when, from the same 21 AHAs, 2301 cases were notified to the ERL and $204(9 \%)$ admitted.

The decline in admission rate during 1978-80 was apparent in all age groups (Table 1). It was also found in children fully vaccinated against pertussis. Thus in 1974-5 809 children given three doses of 
Table 1 Hospital admission rates according to age in 21 area health authorities during 1978-80 and 1974-5

\begin{tabular}{|c|c|c|c|c|}
\hline \multirow[t]{2}{*}{ Age } & \multicolumn{2}{|c|}{$\begin{array}{l}\text { January } 1978 \text { - } \\
\text { June } 1980\end{array}$} & \multicolumn{2}{|c|}{$\begin{array}{l}\text { October } 1974 \\
\text { March } 1975\end{array}$} \\
\hline & $\begin{array}{l}\text { Total } \\
\text { cases }\end{array}$ & $\begin{array}{l}\text { Admitted } \\
\text { to hospital } \\
\text { No }(\%)\end{array}$ & $\begin{array}{l}\text { Total } \\
\text { cases }\end{array}$ & $\begin{array}{l}\text { Admitted } \\
\text { to hospital } \\
\text { No }(\%)\end{array}$ \\
\hline$<4$ mths & 836 & $217(26)$ & 80 & $50(63)$ \\
\hline 4-11 mths & 2395 & $258(11)$ & 285 & 98 (34) \\
\hline $1 \mathrm{yr}-1 \mathrm{yr} 11 \mathrm{mths}$ & 3461 & $126(4)$ & 241 & $20(8)$ \\
\hline $2-5$ yrs & 13712 & $182(1)$ & 1024 & $30(3)$ \\
\hline$\geqslant 6 \mathrm{yrs}$ & 4032 & $17-$ & 671 & 6 (1) \\
\hline Total & 24436 & $800(3)$ & 2301 & $204(9)$ \\
\hline
\end{tabular}

diphtheria/tetanus/pertussis (3 DTP) were notified, and 10 of these were admitted to hospital-a rate of $1 \cdot 2 \%$. In the survey of $1978-80$, there were 13 admissions among 3502 (3 DTP) notifications-a rate of only $0 \cdot 4 \%$. The decline in admission rate was most notable in children over 1 year of age who had not been vaccinated against pertussis, the rate declining fivefold from $9.9 \%$ in $1974-5$ to $2.0 \%$ in 1978-80.

Clinical features. Hospital records for 190 of the 204 admissions in 1974-5 were still available and were examined. The age distribution and the clinical and laboratory features were then compared with those of the 800 admissions in 1978-80. In each outbreak a quarter of those admitted were infants under 4 months of age, although overall, cases were slightly older in 1978-80 (Table 2). The severity and duration of symptoms before admission, the proportion requiring special treatment, and the laboratory findings were similar in both outbreaks (Table 2). The incidence of complications was the same, although convulsions were recorded more often and pneumonia less often in 1978-80. No confirmed cases of encephalitis due to whooping cough were reported among the hospital admissions in either outbreak. There were, however, two differencesin 1978-80 erythromycin was prescribed more and ampicillin less frequently and the mean duration of hospital stay was shorter, particularly in younger children.

Family circumstances. Details of the social class distribution of the notifications (also family size) were available only for the 1978-80 survey, and were as follows: I, II, and III non-manual, $40 \%$; III manual, $41 \%$; IV and V, $19 \%$. This distribution was similar to that for legitimate live births during 1972 and $1978-v i z 37 \%, 41 \%$, and $22 \%$ respectively. ${ }^{4}$ Admission rates were related to social class, being greatest in the disadvantaged classes (Table 3).
Table 2 Comparison of main features of patients admitted to hospital with whooping cough in 21 area health authorities in 1978-80 and 1974-5

\begin{tabular}{lll}
\hline & $1978-80$ & $1974-5$ \\
$(\%)$ & $(\%)$
\end{tabular}

* White cell count $\geqslant 10000$; lymphocytes $\geqslant 50 \%$.

Table 3 Hospital admission rates according to social class* 1978-80 (all ages)

\begin{tabular}{llr}
\hline Social class & Notifications & $\begin{array}{l}\text { Admissions } \\
\text { No (\%) }\end{array}$ \\
\hline I and II & 5904 & $122(2 \cdot 1)$ \\
III non-manual & 2235 & $56(2 \cdot 5)$ \\
III manual & 8370 & $286(3 \cdot 4)$ \\
IV and V & 3803 & $179(4 \cdot 7)$ \\
Others & 1554 & $124(8 \cdot 0)$ \\
Total & 21866 & $767(3 \cdot 5)$ \\
\hline
\end{tabular}

* Excludes 2570 children where the head of the household was in the armed forces or whose occupation was not known.

+ Mainly single parent families and unemployed.

Further analysis has shown that this effect was evident in all age and vaccine groups. Duration of hospital stay varied little between social classes but was affected by family size, the mean duration of stay being 10 days for only children and 16 days for those with two or more siblings aged under 6 years.

There was a considerable difference in the social class distribution of totally unvaccinated children and those who, although unvaccinated against pertussis, had received three doses of diphtheria/ tetanus (3 DT) vaccine (Table 4). In consequence, for children aged 1-5 years, the admission rate of those who had received 3 DT $(1.4 \%)$ was lower than of those totally unvaccinated $(4 \cdot 8 \%)$. 
Table 4 Social class distribution of cases not vaccinated against pertussis and aged 1-5 years in 1978-80

\begin{tabular}{lll}
\hline $\begin{array}{l}\text { Social } \\
\text { class }\end{array}$ & $\begin{array}{l}\text { Diphtheria/tetanus } \\
\text { vaccine } \\
\text { No }(\%)\end{array}$ & $\begin{array}{l}\text { Totally } \\
\text { unvaccinated } \\
\text { No } \%)\end{array}$ \\
\hline $\begin{array}{l}\text { I, II, III non-manual } \\
\text { III manual }\end{array}$ & $4086(43)$ & $280(22)$ \\
IV, V, others & $3488(37)$ & $482(38)$ \\
Total & $1886(20)$ & $521(41)$ \\
\hline
\end{tabular}

\section{Deaths}

During the 1974 outbreak in England and Wales, there were 25 deaths among the total 25135 whooping cough notifications $(1 / 1000)$ compared with 23 deaths among the total $99438(1 / 4000)$ in the 1977 outbreak. The decline in death rate, although greatest between age 3 months and 1 year, was apparent in all age groups (Table 5).

Hospital records were examined for 18 of 25 deaths during the 1974 outbreak and 22 of 23 during the 1977 outbreak. In infants aged under 3 months deterioration was rapid, death occurring on average 9 days after admission. In one extreme instance an infant from whom Bordetella pertussis was isolated at necropsy developed a cough when 8 days old and died four days later. The course of the illness in the children aged 3 months to 1 year was usually more prolonged than in younger infants, and some died more than one month after entering hospital. Most of the children aged over 1 year who died were already chronically ill when they developed whooping cough. There was a suggestion that treatment was more prompt and intensive during the 1977 outbreak. Thus all infants under 3 months of age who died in that outbreak had been admitted within a week of the onset of symptoms and, with one exception, had received ventilatory support. In contrast, in the 1974 outbreak only three of the 10 infants in this age group who died were artificially ventilated and four had been ill for two or three weeks before admission.

Death rates from whooping cough were also affected by social class. In the 1977 outbreak children in social classes IV, V and 'others' accounted for $25 \%$ of the notifications in the ERL study (Table 3 ) whereas $48 \%$ (11 of 23 ) of the children who died in England and Wales were in these social classes. The excess was most notable in the age group 3 to 12 months. Taking both outbreaks together, 15 of 18 deaths $(83 \%)$ at this age were in children from social classes IV, V, and 'others'.

\section{Discussion}

Since the decline in pertussis immunisation there has been an unexpected fall in whooping cough admission and death rates-a fall that has affected children of all ages and vaccination status. There is, however, no evidence of a recent change in the basic character of the disease; the clinical features and complications in children admitted to hospital or dying from whooping cough have remained essentially unchanged. The duration of hospital stay has decreased but this does not necessarily imply a lessening of severity since the findings show that family circumstances also determine when a child is discharged. A trend towards earlier discharge has also occurred for other diseases in recent years. ${ }^{5}$

A number of factors other than disease severity affect the proportion of notified children admitted to hospital or dying from the disease. Firstly, there is the proportion of cases notified. Although OPCS notification rates in the 1977 outbreak were four times greater than those in the 1974 outbreak, other sources $^{6}$ suggest that the real increase in the incidence of the disease was only twofold. It seems likely that notifications were inflated by more complete reporting of milder cases-a result of the publicity surrounding the disease in recent years. Nevertheless, even taking this into account, a considerable decline in admission and death rates remains.

Secondly, whooping cough admission and death rates were found to be strongly affected by social class. It is possible that with the decline in pertussis immunisation there has been a change in the social class distribution of the disease. After 1974 many parents refused to have their children immunised with DTP and opted instead for immunisation with

Table 5 Death rates according to age 1977-9 and 1974-5

\begin{tabular}{|c|c|c|c|c|c|c|c|}
\hline \multirow[t]{2}{*}{ Age } & \multicolumn{3}{|c|}{ July 1977-June 1979} & \multicolumn{3}{|c|}{ January 1974-December 1975} & \multirow{2}{*}{$\begin{array}{l}\text { Relative death } \\
\text { rates } \\
1977-9: 1974-5\end{array}$} \\
\hline & Deaths & Notifications & $\begin{array}{l}\text { Deaths } / 1000 \\
\text { notifications }\end{array}$ & Deaths & Notifications & $\begin{array}{l}\text { Deaths } / 1000 \\
\text { notifications }\end{array}$ & \\
\hline$<3 \mathrm{mths}$ & 11 & 1239 & 8.9 & 10 & 489 & $20 \cdot 4$ & $1: 2 \cdot 3$ \\
\hline 3-11 months & 6 & 8911 & 0.7 & 12 & 3080 & 3.9 & $1: 5 \cdot 8$ \\
\hline $1-9$ years & 6 & 81278 & 0.07 & 3 & 19351 & $0 \cdot 15$ & $1: 2 \cdot 1$ \\
\hline
\end{tabular}


DT. In consequence, much of the increase in notifications in the 1977-80 outbreak arose in DT immunised children many of whom, unlike totally unvaccinated children, come from the more advantaged social classes. In 1974-5, DT vaccine was little used and a large proportion of the notifications arose in totally unvaccinated children, ${ }^{2}$ many of whom presumably came from the disadvantaged groups who are especially likely to be admitted to hospital. Such a shift would reduce hospital admission rates in the $1977-80$ outbreak particularly, as the findings show, in older children unvaccinated against pertussis.

An increase in the proportion of cases notified and the changes in social class distribution might account for the decline in the death rate for infants aged under 3 months and for those over 1 year, but these factors do not adequately explain the pronounced decline in the number of deaths in infants aged 3 months to 1 year. In children of this age the number of deaths actually declined by half despite a very large increase in notifications. Increased awareness leading to improvements in care seem the most likely explanation. In this group deaths occur predominantly in the more disadvantaged social classes. The substantial reduction in death rate may have been achieved by earlier recognition and treatment of the disease among these children. These factors might well exert a lesser influence in very young infants dying rapidly from overwhelming infection and older children already compromised by chronic disease. The only specific change in treatment found in the study was the replacement of ampicillin by erythromycin. The latter seems to be more effective in reducing complications, especially pneumonia. ${ }^{7}$ There was also a suggestion from the findings that assisted ventilation was more readily employed in recent years. These two changes may have reduced mortality.

In summary, therefore, the findings suggest that the decline in hospital admission and death rates in the 1977 outbreak had three causes; an increase in the proportion of mild cases notified, a change in the social class distribution of cases resulting from a change in vaccination pattern, and improved care.
There is no evidence that the disease itself has become milder in recent years. During outbreaks whooping cough continues to be a frequent cause of hospital admission in young children. The drop in admission rates should not be allowed to obscure the increase in the total number of whooping cough admissions since pertussis vaccination declined. ${ }^{5}$ Those most likely to be admitted to hospital or to die are children from the more disadvantaged social classes. This may reflect nursing difficulties in adverse social conditions rather than the severity of attacks. Whatever the reason, the consequences of whooping cough are clearly worse for families in poor social conditions. Children with chronic disease are also at increased risk and every effort should be made to bring both these vulnerable groups into the vaccination programme. Finally, the findings reaffirm the risk to the very young infant. A vaccination schedule which is often not completed until almost the end of the first year of life is inadequate.

The help of the paediatricians in the Areas concerned is gratefully acknowledged.

\section{References}

1 Robinson DA, Mandal BK, Ironside AG, Dunbar EM. Whooping cough-a study of severity in hospital cases. Arch Dis Child 1981;56:687-91.

${ }^{2}$ Miller CL, Fletcher WB. Severity of notified whooping cough Br Med J 1976;i:117-9.

${ }^{3}$ Public Health Laboratory Service. Efficacy of pertussis vaccination in England. $\mathrm{Br}$ Med $J$ 1982;285:357-9.

4 Office of Population Censuses and Surveys. Birth statistics 1978. London: HMSO, 1978.

5 Office of Population Censuses and Surveys. Hospital in-patient enquiry for the years 1974-1978. London: HMSO, 1978.

6 Miller E, Jacombs BI, Pollock TM. Whooping cough notifications (letter). Lancet 1980;i:718.

${ }^{7}$ Islun J, Anglin CS, Middleton PJ. The whooping cough syndrome: a continuing paediatric problem. Clin Pediatr (Phila) 1975;14:171-6.

Correspondence to $\mathrm{Dr}$ E Miller, Epidemiological Research Laboratory, Central Public Health Laboratory, Colindale Avenue London NW9 5HT.

Received 10 October 1983 